\title{
STUDY ON THE DURATION OF OPERATIONS PERFORMED BY TRANSPORT VEHICLES DURING UNLOADING OF THE GRAIN HARVESTER HOPPER
}

\author{
Galin Tihanov \\ Department of Agricultural Engineering, Faculty of Agriculture, \\ Trakia University, Bulgaria \\ Studentski grad, 6000 Stara Zagora, Bulgaria \\ e-mail: galin.tihanov@abv.bg
}

\begin{abstract}
Unloading time of the harvester hopper at standstill depends also on the duration of the operations performed by the transport vehicle as time from the commencement of the harvester signalling to the start of the transport vehicle and the time from the start of the transport vehicle till its arrival under the unloading screw of the grain harvester. The time measuring of the operations established that the average time of commencement of the harvester signalling until the start of the transport vehicle was $215.5 \mathrm{~s}$, and the time for moving of the transport vehicle to the grain harvester was $222 \mathrm{~s}$. It was found that in $49 \%$ of the duration of the operations the drivers of the transport vehicles wait before going to the grain harvester (from the total of $437.5 \mathrm{~s}$ ). This is due to the incorrect setting of the time of commencement of the first level signalling, which prevents drivers from starting and respectively arriving at the exact moment at the harvesters. It has also been found that the unloading of the harvester grain hopper takes place immediately after the arrival of the transport vehicles at it and therefore a non-filled hopper is unloaded. As a result, about $1 \mathrm{~m}^{3}$ of the harvester hopper is not used and also the number of its stops for unloading increase by about $11 \%$, practically reducing its productivity.
\end{abstract}

Keywords: grain harvester, unloading the grain harvester hopper, productivity, signaling about the grain level in the hopper, joint work of harvester and transport vehicle.

\section{INTRODUCTION}

Harvesting of cereals is one of the main activities in agriculture and has to be carried out for a short period of time - a maximum of 10-12 days in order to avoid high losses from spillage of the grain and to reduce the risk of harvest destruction from natural conditions [1]. Moreover, some authors have identified options for growing the grain crop [2]. Of great importance in harvesting cereals is the overall logistics of the process, as well as the proper organization [3]. Also, the organization of the harvest can have a significant impact on the productivity of grain harvesters [4]. The lack of such coordination (organization) is a prerequisite for idle times that lead to an extension of the harvest period [5]. Otherwise, one of the following negative results may occur:

1. Incomplete filling of the harvester hopper and inefficient use of the load capacity of the transport vehicles when the vehicle reaches the harvester before filling the hopper;

2. Increase of the field tramping by the transport vehicles when they move to the harvester waiting for the filling of its hopper;

3. Decrease the productivity of the grain harvester due to stopping when the hopper is full and waiting for the arrival of a transport vehicle.

The first and third cases normally occur when the unloading of the harvester hopper takes place in standstill, while the second one is more typical of unloading in motion. Unloading of

IRTTE Vol. 6, No. 3, 2018 ISSN 1314-8788 (print), ISSN 1314-8796 (online), doi: 10.15547/artte.2018.03.004 


\section{IRTIIE

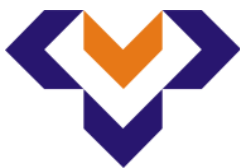 \\ Ipplied Resseirlches in Technics, Technologies ind Bductation \\ Journal of the Faculty of Technics and Technologies, Trakia University \\ https://sites.google.com/a/trakia-uni.bg/artte/}

harvesters in motion also does not preclude the need to use of signaling for grain hopper filling. Even when unloading in motion, it is still necessary to unload in standstill - over $18 \%$ of the unloadings [6]. Information technology based logistics systems are increasingly being used to exchange information and synchronize the work of harvesters with the transport vehicles [7-9]. Although in this case harvesters are equipped with a device for measuring the quantity of grain entering the hopper (quantimeter), level alert sensors are also used [5].

Great part of the harvesters do not have such systems and their connection to the transport vehicles is made only by signalling made by the harvester when its hopper is full. In modern grain harvesters there are two critical levels that are automatically signalled by all means: first level - when filling a certain volume from the hopper and the second level - when the entire hopper is filled [10]. Practically, through the signalling of the harvesters, their joint work with the transport vehicles is coordinated.

In our country, in about $90 \%$ of agricultural farms unloading of the hopper is made in standstill [3]. The hopper unloading time also depends on the duration of the operations (activities) performed by the transport vehicle, such as time from commencement of the harvester signalling till start the transport vehicle and time from departure of the transport vehicle till its arrival under the harvester unloading screw. These times vary considerably as they are largely influenced by the overall organization of the harvesting process. It has been found that in good organization the waiting time of the transport vehicle has been 9,25 min within one shift and in poor organization it has been 54,9 $\min$ [11]. Also, in the case of premature unloading of incomplete hoppers, the load capacity of the transport vehicle is not effectively utilized [12].

The objective of the study is to investigate and establish the duration of operations performed by the transport vehicles when unloading the grain harvester hoppers in standstill.

\section{MATERIAL AND METHODS}

The survey was conducted during the harvest campaign of 2018, without altering the harvest organization. The study was carried out with a K1 harvester with technical parameters: 6,10 $m$ working width of the header, $9 \mathrm{~m}^{3}$ volume of the grain hopper and $110 \mathrm{l} / \mathrm{s}$ flow rate of the unloading screw. The harvester was serviced by two transport vehicles (TV 1 and TV 2) with load capacity of $8 t$. The harvested crop is wheat, Enola variety with volumetric weight of 720 $\mathrm{kg} / \mathrm{m}^{3}$ at an average yield of $650 \mathrm{~kg} / \mathrm{da}$, and average humidity measured by the on-board grain harvester humidity meter $-12.3 \%$. The grain harvester had two levels of automatic signalling of filled hopper. Unloading of the grain hopper was done at standstill of the harvester and the first level signalling was switched on at about $70 \%$ filling of the volume of the grain hopper. The time from switching the harvester signaling till the start of the transport vehicle $\left(t_{1}\right)$ and the times from the start of the transport vehicle till arrival under the unloading screw of the grain harvester $\left(t_{2}\right)$ is determined by measuring, with their minimum, maximum and average values.

\section{RESULTS AND DISCUSSION}

Table. 1 show the results for the time from the commencement of the first-level signalling to the departure of the transport vehicles. This is the driver response time $\left(t_{1}\right)$ to the signal made by the harvester. The table shows that the transport vehicles go to the harvester on average $215.5 s$ after switching on the first-level signalling. The transport vehicle TV 1 starts considerably later $368 s$ than the second transport vehicle TV $2-63 s$. 
Table 1. Time of commencement of harvester signalling to start of the transport vehicles (driver response time $-t_{1}$ )

\begin{tabular}{|c|c|c|c|c|}
\hline \multirow{2}{*}{ Transport vehicle } & \multirow{2}{*}{$\begin{array}{l}\text { Number of } \\
\text { measurements }\end{array}$} & \multicolumn{3}{|c|}{$\begin{array}{l}\text { Time of commencement of harvester signalling to start } \\
\text { of the transport vehicle, } t_{1}, s\end{array}$} \\
\hline & & $t_{1_{\min }}$ & $t_{1_{\max }}$ & $\overline{t_{1}}$ \\
\hline TV 1 & 17 & 193 & 536 & 368 \\
\hline TV 2 & 17 & 27 & 95 & 63 \\
\hline & Average, $s$ & 110 & 315.5 & 215.5 \\
\hline
\end{tabular}

The results of the studies of the time for moving of the two transport vehicles to the grain harvester $t_{1}$ are shown in Table 2. The average time for movement of the transport vehicles is $222 s$, ranging from $46 s$ to $398 s$. It is noticed that the average time for movement of the first transport vehicle TV 1 is $46 s$ and is significantly less than the average time of the transport vehicle TV $2-398 s$. It has been found out that both transport vehicles did not immediately start to the harvester upon switching the first-level hopper filling signal, but were waiting for a certain period of time. The waiting time is the least for transport vehicle TV 2(Table 1), where the average movement time is the greatest(Table 2). On that farm the transport vehicle reaches the harvester much before filling the hopper and continues to move until it is $100 \%$ filled. Naturally, the transport vehicle travels a longer distance, which is associated with unnecessary overtramping of the field and increased fuel consumption. The transport vehicle TV 1 starts significantly later after the first-level signaling for the hopper filling, but also arrives before the second level harvester signalling is switched on. Most often the unloading is carried out immediately and therefore an incomplete hopper is unloaded.

Truck weight receipts show that the two transport vehicles at each course carried between $5647 \mathrm{~kg}$ and $6094 \mathrm{~kg}$ or an average of $5871 \mathrm{~kg}$. With a bulk density of wheat $720 \mathrm{~kg} / \mathrm{m}^{3}$, this gives a volume of $8.15 \mathrm{~m}^{3}$. Having in mind that the hopper volume is $9 \mathrm{~m}^{3}$ it is evident that about $1 \mathrm{~m}^{3}$ of the hopper was not used or the number of stops was increased by $11 \%$. In practice, this leads to lower productivity of the grain harvester.

Table 2. Time for moving of the transport vehicles to the grain harvester

\begin{tabular}{|c|c|c|c|c|}
\hline \multirow{2}{*}{ Transport vehicle } & \multirow{2}{*}{$\begin{array}{c}\text { Number of } \\
\text { measurement }\end{array}$} & \multicolumn{3}{|c|}{ Time for moving of the transport vehicles to the grain } \\
& & $t_{2 \min }$ & $t_{2 \max }$ & $\overline{t_{2}}$ \\
\cline { 3 - 5 } & 17 & 15 & 76 & 46 \\
\hline TV 1 & 17 & 113 & 553 & 398 \\
\hline TV2 & Average, $s$ & 64 & 314.5 & 222 \\
\hline
\end{tabular}

From a purely practical point of view, the time from switching the first-level signalling for the hopper filling until arrival of the transport vehicle to the grain harvester to unload its hopper $t_{m}$ is determined by the expression:

$$
t_{m}=t_{1}+t_{2}=215.5+222=437.5 \mathrm{~s}
$$

That is, the time during which the drivers of the transport vehicles wait before going to the harvester (the driver response time) is almost the same as the time for movement to the harvester $-49 \%$ vs. $51 \%$. Therefore, the incorrect setting for switching of the first-level signalling does not allow drivers to start and respectively arrive at the right moment at the 


\section{ART'TIE

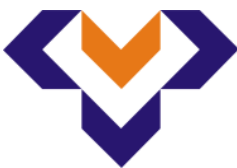 \\ Ipplied Resseirldes in Technics, Technologies and Bductation \\ Journal of the Faculty of Technics and Technologies, Trakia University https://sites.google.com/a/trakia-uni.bg/artte/}

harvesters, but rather confuses them. They intuitively choose the time of departure and this results in unloading of an incomplete hopper, unnecessary movement of the transport vehicle in the field and, ultimately, lower productivity of harvesters and the transport vehicles.

\section{CONCLUSIONS}

It has been found out that the average time from the commencement of the harvester signalling to the start of the transport vehicle is $215.5 \mathrm{~s}$ and the time for moving of the transport vehicle to the grain harvester is $222 \mathrm{~s}$.

It has been found out that in $49 \%$ of the duration of the operations the drivers of the transport vehicles wait before going to the grain harvester (from a total of $437.5 \mathrm{~s}$ ).

It has been established that the unloading of the harvester grain hopper takes place immediately after arrival of the transport vehicles to it and therefore an incomplete hopper is unloaded. As a result, about $1 \mathrm{~m}^{3}$ of the harvester hopper has not been used and the number of its stops for unloading has increased by about $11 \%$, practically leading to a decrease in its productivity.

\section{REFERENCES}

[1] Nikolov N., Petev D. \& Vassilev V. (1974). Agricultural machinery. Zemizdat, Sofia, p. 317.

[2] Ivanova M., Dospatliev L., Stoyanova A. \& Valchev N. (2017). Possibilities of wheat farming on soils contaminated with heavy metals in the region of NFMW-Plovdiv, Bulgaria. Applied Researches in Technics, Technologies and Education, Vol. 5, No. 2, pp. 131-142.

[3] Delchev N., Trendafilov K., Tihanov G. \& Stoyanov Y. (2016). Grain combines productivity according to various unloading methods - in the field and at the edge of the field. Agricultural science and technology, Vol. 8, No. 3, 2016, pp. 221-226.

[4] Trendafilov K. \& Dragoev D. (2017). Study on the place of grain hopper unloading on the grain harvester productivity. Proceedings of International Scientific Conference „Technics, Technologies and Education" ICTTE 2017, Faculty of Technics and Technologies of Yambol, Trakia University, Yambol 19-20.10.2017, pp. 26-31.

[5] Tihanov G., Kolev B., Trendafilov K., Delchev N. \& Stoyanov Y. (2017). Justification of the method for determining the moment for switching on the level one signaling of filled grain harvester hoppers. Agricultural science and technology, Vol. 9, No. 3, 2017, pp. 218-222.

[6] Niehaus Ch. (2014). Evaluation of corn harvesting operations with the use of georeferenced data. University of Illinois at Urbana-Champaign, 2014.

[7] Telematics: Wireless Communication and Data Transfer. (2012). Precision Agriculture Series, Timely Information, Agriculture, Natural Resources \& Forestry, Alabama Cooperative Extension System, September 2012, [Online], Available: www.AlabamaPrecisionAgOnline.com.

[8] Machine Sync. (2013). Accelerating the fall harvest with John Deere Machine Sync, September 2013, Available: http://blog.machinefinder.com/16353/accelerating-fallharvest-john-deere-machine-sync.

[9] Claas Group. (2015). Less stress but more efficiency in field logistics, 2015, Available: http://www.claas-group.com/press-public-relations/press-releases/less-stress-butmoreefficiency-in-field-logistics/657124. 


\section{IDTILCY Journal of the Faculty of Technics and Technologies, Trakia University https://sites.google.com/a/trakia-uni.bg/artte/}

[10] Tihanov G. (2017). Study of grain harvester hopper unloading time at standstill in relation to optimizing their productivity. Dissertation paper for awarding Doctor's educational and scientific degree, Ruse University „Angel Kanchev“, Ruse, 2017, p.140.

[11] Lhagvasuren S. \& Byambadorge Ch. (2013). Comparative study of grain harvesters. Proceedings of International scientific practical conference for yound scientists «Scientific research and development for implementation in the Agroindustrial complexes», 17-18 April 2013, Part II, pp. 233-236.

[12] Delchev N. \& Trendafilov K. (2002). Effect of grain harvester hopper volume on their productivity when unloading at standstill. Agricultural machinery, No. 3, pp. 19-22. 